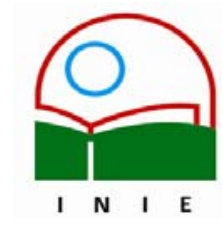

Universidad de Costa Rica

Facultad de Educación

Instituto de Investigación en Educación

ACTUALIDADES INVESTIGATIVAS EN EDUCACION

\title{
EL APRENDIZAJE ÉTICO EN LA CONSTRUCCIÓN DE LA CIUDADANÍA DEMOCRÁTICA ${ }^{1}$
}

\author{
María del Pilar Zeledón Ruiz²
}

\section{La formación ética de la persona humana: reto de la sociedad postmoderna}

Un breve recorrido por la panorámica mundial nos permite reconocer las profundas transformaciones sociales, económicas, políticas y culturales por las que transitan las distintas sociedades. En estos procesos de cambio, encontramos un eje regulador que incide directa o indirectamente en los avances o retrocesos alcanzados: la formación ética.

La caracterización que se hace de las sociedades postmodernas en el siglo XXI nos habla de una época en que la confusión, desesperanza, miedos e inseguridades desorientan al ser humano del propio sentido de su existencia. Por una parte, el campo científico y tecnológico ha sido testigo del enorme potencial que ha desarrollado el hombre a lo largo de la historia, pero por otra, los niveles de violencia, egoísmo, corrupción e indiferencia se acrecientan significativamente en un mar de contradicciones. Grandes masas humanas carecen de las condiciones mínimas para vivir dignamente. Las guerras y el terrorismo atentan sin piedad a los sectores más vulnerables haciendo que las grietas sociales sean cada vez más profundas. Sin duda, la sed insaciable de poder anima a los grupos hegemónicos a expandir sus propios ideales, sin detenerse en las consecuencias que dejan a su paso.

Pareciera que este panorama tan sombrío nos quiere impulsar a perder la esperanza en las posibilidades de cambio, en la credibilidad

\footnotetext{
${ }^{1}$ Conferencia Congreso Internacional de Investigación Educativa:"Investigar para transformar" Instituto de Investigación en Educación-Universidad de Costa Rica, COSTA RICA. 2 de febrero de 2005

2 Profesora asociada de la Universidad de Costa Rica. Co-coordinadora del Programa Nacional de Formación en Valores de Costa Rica (1999-2001). Premio Nacional Aquileo J. Echeverría, 2000.
} 
en el ser humano para reconstruir los pilares de la civilización, como lo afirmara Hanna Arendt (1998) en una de sus importantes obras.

Pensar que es posible lograr una sociedad en la que TODOS encontremos unos mínimos de justicia y equidad social que favorezcan el logro de unos máximos de felicidad requiere un nuevo tipo de aprendizaje humano en donde la piedra angular lo constituya la ética.

El enfoque de aprendizaje ético procura formar a las nuevas generaciones en las condiciones básicas para lograr la optimización de la persona, tanto en su dimensión singular como social. De esta manera, el ser humano será capaz de construir su felicidad a lo largo de su recorrido biográfico mediante un proceso de encuentro consigo mismo, con el otro (a) y lo otro (ética de la alteridad, ética de la compasión, ética de la acogida) (Buber, 1998; Levinas, 2003, Ricoeur, 1993). Como bien lo afirman Martínez, Buxarrais y Esteban (2002),

Las sociedades postindustriales democráticas, inmersas en procesos de globalización económica, confiadas en las nuevas tecnologías de la información y la comunicación y con nuevos retos presentes y futuros como son la acogida de personas de otros países y la consecuente convivencia de diferentes culturas, religiones y costumbres, necesitan más que nunca ciudadanos con rasgos éticos. (Martínez, 2002)

Por lo tanto, para favorecer este proceso, es necesario atender los cuatro niveles de optimización humana sugeridos por Martínez (1998, 2001): la dimensión codificativa, adaptativa, proyectiva e introyectiva.

La dimensión codificativa hace referencia a las capacidades para captar la información, entender los contenidos informativos y los sistemas conceptuales más elementales, que le permiten apropiarse de los conocimientos necesarios para desempeñarse eficientemente en un mundo en constante transformación. La segunda, la dimensión adaptativa, se refiere a la conducta y formas de proceder que le ayudan a la persona a autorregular su comportamiento, de esta manera se incorpora conscientemente en un proceso de enculturación que le aporta a su crecimiento humano.

Dentro de estas dos dimensiones la referencia social desempeña un papel muy importante como modulador del proceso pues generalmente, el ser humano se detiene en los otros para recoger algunas muestras de lo que se asume como correcto-incorrecto, permitido-prohibido, adecuado-inadecuado. Un claro ejemplo lo constituyen los niños cuando miran a sus padres o encargados para 
obtener alguna indicación de lo que se supone que deben hacer (Coles, 1997). La aprobación verbal o gestual que reciben se convierte en un indicador de lo que se supone es aceptable dentro de ese contexto o lo que debería evitarse.

El tercer nivel lo constituye la dimensión proyectiva, donde la persona es capaz de adaptarse a las normas externas, pero también crear sus propias regulaciones y actuar en función de éstas. Cuando nos desempeñamos como profesionales en cualquier disciplina, debemos atender una cierta reglamentación que nuestro trabajo establece (debemos asumir unas ciertas tareas, cumplir un horario determinado, relacionarnos de una cierta manera con quienes nos rodean), pero aún cuando exista una cierta normativa, somos nosotros los que le impregnamos un cierto estilo personal al ejercicio laboral. Nos planteamos unas pautas determinadas para mejorar nuestro trabajo, ordenamos nuestras tareas bajo ciertas prioridades, nos comunicamos bajo ciertas premisas, valoramos la presentación personal bajo algunos criterios, en fin proyectamos una manera particular de ser como personas y trabajadores, como ciudadanos comprometidos y responsables.

Finalmente, la dimensión introyectiva, permite que la persona además de crear patrones o valores, sea capaz de darse cuenta de que ella misma es quien está actuando. Por lo tanto, encontramos una estrecha relación con los procesos de conciencia y autoconciencia, con la capacidad de autodeterminación personal que permite un claro reconocimiento de ese SER y ESTAR en el mundo.

A partir del desarrollo de estas dimensiones, la conciencia se estructura como un regulador moral, que emerge en la interacción social mediada por el lenguaje y cuyo carácter intersubjetivo se fundamenta en el diálogo. Esta disposición del sujeto, de índole funcional le permite articular el significado conflictivo de la información moral que recoge del medio con un tipo de juicios y acciones que posibilitan una respuesta adecuada a los problemas sociomorales. Por lo tanto, se debe procurar que,

...las diferentes matrices de valores que cada persona pueda construir a lo largo de su vida estén orientadas a que valores como justicia, igualdad, libertad, solidaridad, respeto, tolerancia activa y actitud de diálogo, sean apreciados como tales y denunciada su ausencia. Para ello es necesario un modelo de formación ética que suponga el aprendizaje del ejercicio de la responsabillidad y entender la dignidad humana como valor guía, lo que quiere decir 
proponer un modelo de vida tanto individual como colectivo que no sólo facilite niveles de felicidad personal sino el ejercicio de una ciudadanía comprometida con el bien común y con el logro de una sociedad más equitativa (Martínez, Buxarrais y Esteban, 2002).

Desde la organización cotidiana que se vive en el hogar hasta la complejidad de las relaciones que se establecen en los diferentes ámbitos de la sociedad (educativo, político, económico, social), los procesos comunicativos que se establecen, los proyectos que se formulan, los valores que se vivencian en los distintos momentos de encuentro (respeto, responsabilidad, libertad, justicia, igualdad, tolerancia, confianza) son elementos determinantes en el cimiento de las bases de una ciudadanía democrática que parte de la realización personal y comunitaria de sus protagonistas, tal como lo analizaremos en el siguiente apartado.

\section{El aprendizaje ético y la ciudadanía democrática: elementos claves de la transformación}

La ciudadanía se ha convertido a lo largo de los años en un constructo histórico que ha sido objeto de infinidad de matizaciones. Desde las aproximaciones que Aristóteles ofreciera en su reconocida obra La Política, al considerar la polis (lo público) como el ámbito propio de la ciudadanía frente al oikos (lo privado) este concepto ha inspirado a grandes pensadores, filósofos, políticos, sociólogos y pedagogos sobre la complejidad y trascendencia no sólo de su contenido, sino también de sus implicaciones en los diferentes ámbitos de la vida socio-económica y cultural de los estados- nación ${ }^{3}$ (Arendt 1968,1992,1998; Held 1996;2001 Habermas 1990; Giddens 1994; Pettit 2000; Gutman 1999; Cortina 1992,1997,2000,2001, entre otros).

Encontramos numerosas obras, tratados, seminarios, congresos, conferencias, proyectos y reformas educativas que invitan a la reflexión,

\footnotetext{
${ }^{3}$ La mayoría de los politólogos han sostenido que las teorías que desarrollan deben operar dentro de los límites del Estado-nación. Cuando desarrollan principios de justicia para evaluar sistemas económicos se centran en las economías nacionales; cuando analizan principios jurídicos para evaluar constituciones se acojen a las constituciones nacionales, cuando estudian un conjunto de virtudes apropiadas e identidades requeridas para una ciudadanía democrática se preguntan lo que significa ser un buen ciudadano en un Estado-nación; cuando discuten lo que puede o debe significar 'comunidad política', están indagando en qué sentido los Estados-nación pueden verse como comunidades políticas. [Cfr. Cosmopolitismo, estados-nación y nacionalismos de las minorías: un análisis crítico de la literatura reciente de Kymlicka \& Straehle en http://www.xtec.es/ asarsane/Article15.htm]
} 
comprensión y actuación de las exigencias que conlleva el ejercicio de la ciudadanía, por lo que sin duda, intentaremos esbozar algunas apreciaciones en torno a la relación que podemos encontrar entre la ciudadanía democrática y el aprendizaje ético como elementos básicos en los procesos de transformación que las sociedades necesitan para construirse bajo condiciones de justicia, igualdad y solidaridad para todos. De seguro quedarán muchos otros elementos a considerar, que por las limitaciones de tiempo y espacio no podremos tratar con la profundidad que quisiéramos, pero precisamente la actualidad de este tema no sólo revela su importancia, sino también el carácter inagotable de su estudio para generar nuevas rutas de apreciación, aprehensión y actuación.

Al parecer la noción de ciudadanía recoge los esfuerzos que tanto liberales como comunitarios sostienen desde sus respectivos paradigmas. Por una parte, los liberales se interesan por el diseño racional de una sociedad justa y, por otra, los comunitaristas resaltan la necesidad de pertenencia a una comunidad. Como se deriva del planteamiento de Kymlicka y Norman (1994), la noción de ciudadanía tendría el mérito de unir las dos perspectivas: lo "racional" derivado de la justicia y lo "sentimental" contenido en la pertenencia.

También los que abogan por recuperar, desde una perspectiva moderna, la tradición republicana de Roma y la experiencia republicana italiana durante el período renacentista, acuden a la noción de ciudadanía para establecer una mediación entre los defensores del liberalismo y del comunitarismo. En los últimos años, el trabajo de Phillip Pettit es una muestra del creciente interés que está despertando la complementariedad de tales argumentaciones. Su clásica obra Republicanism. A theory of freedom resulta inspiradora para quienes pretenden encontrar otra voz que se ajuste a sus expectativas y proyectos bajo criterios de responsabilidad, libertad y justicia.

Camps $(2004$, p. 5) refiriéndose a la obra de Pettit señala,

El republicanismo no aboga sólo por un ciudadano que no sea siervo, sino asimismo por un ciudadano que ejerza realmente de ciudadano. Para decirlo en términos aristotélicos y me temo que anacrónicos: la república precisa de ciudadanos virtuosos, capaces de adquirir aquellas virtudes o valores que la democracia y el estado de derecho exigen. Pues la república debe ser una 
comunidad política de ciudadanos activos que comparten y procuran realizar un conjunto de valores comunes.

Y, al plantear el republicanismo como una corrección del liberalismo señala esta misma autora,

El individuo que ha ido ganando espacios de libertad no siempre sabe ejercer bien la libertad: tiene que aprender a no abusar de ella, a no dominar a otros, a respetar también la libertad de los demás. En las democracias liberales de nuestro tiempo se echan de menos las buenas costumbres que reclamaba Maquiavelo a los ciudadanos de las repúblicas renacentistas, o los hábitos del corazón que Tocqueville descubrió en los miembros de la incipiente democracia americana. Es eso lo que significa el civismo, la moral mínima necesaria para vivir pacíficamente todos juntos (Camps, 2004).

También, las aportaciones de Hannah Arendt resultan iluminadoras dentro de la tarea que nos ocupa, especialmente aquéllas relacionadas con la pluralidad, la acción y la esfera pública. Su extensa producción académica y su singular actuación en el panorama socio-político que le correspondió vivir, la han convertido en una de las figuras claves del pensamiento filosófico-político del siglo XX.

Su obra La condición humana y sus ensayos reunidos bajo el título Entre el pasado y el futuro ofrecen un análisis detenido sobre las consecuencias negativas del triunfo de la modernidad, tales como el papel hegemónico de la labor (homo laborans) frente a la acción (homo politicus) y la desaparición del espacio público en el que se desvanece la ciudadanía misma. Frente a la labor y al trabajo (dimensiones de la actividad humana) la acción emerge a partir de la pluralidad y posibilita la concresión de las iniciativas.

Por lo tanto, potenciar el espacio público se hace necesario para lograr que la libertad y la igualdad se revelen y los sujetos interactúen mediante el habla y la reflexión en un contexto donde afloren sus propias identidades, evalúen sus acciones y descubran experiencias mediante procesos de deliberación colectiva en temas de interés común. Consecuentemente, la construcción de la ciudadanía requiere la formación de la naturaleza política del hombre y es ahí donde el aprendizaje ético que se deriva tanto de la cultura familiar como de la escolar en los diferentes niveles y espacios formales, no formales e 
informales desempeñan una función esencial para activar los mecanismos de transformación que requieren en la sociedades contemporáneas, en donde la cultura mediática también juega un papel fundamental en la movilización de voluntades.

Pero ¿qué es lo que queremos transformar?, ¿por qué debemos trabajar por esa transformación?, ¿cómo podríamos lograr esos cambios? y ¿cuáles metas inspiran esas transformaciones?, son algunas de las interrogantes que podríamos eventualmente plantearnos y sugerir desde nuestra propia visión y experiencia algunas posibles respuestas, las cuales se conjugan con las reflexiones que a lo largo de este congreso se han formulado.

\section{Educar para ser mejores personas y comprometidos ciudadanos}

La transformación de nuestras sociedades empieza por la búsqueda del cambio personal, que active el ámbito social, cultural y político. Necesitamos urgentemente una nueva actitud frente a la vida, frente a lo que queremos y podemos aspirar. Eso implica crear las condiciones para que emerjan aprendizaje éticos que inviten a las personas a ser mejores. Como bien lo expresaba el lema del Programa Nacional de Formación en Valores en el que trabajamos hace algunos años: SIEMPRE PODEMOS SER MEJORES...

Pero ¿qué significa ser una mejor persona? La aproximación que podríamos dar a esta pregunta podría estar sujeta a una serie de interpretaciones. De seguro, el contexto socio-histórico y cultural desde donde intentemos perfilar estos rasgos nos muestra la complejidad de encontrar una posible respuesta. Sin embargo, a pesar de las variaciones que eventualmente se podrían derivar, podemos considerar que una persona que se esfuerce por desarrollar su humanidad, su dignidad es capaz de conformar pensamientos, afectos y conductas que le ayudan a construir su autonomía, a plantearse leyes por sí mismo, a autolimitarse, pero para lograrlo requiere de la solidaridad de todos, donde cada quien ponga lo mejor de su parte para que todos resulten beneficiados. Por esta razón, las normas morales deben ayudar a respetar y potenciar a todas las personas, no favorecer a unos en perjuicio de otros.

La tradición kantiana nos habla de dos grandes máximas: "obra de tal modo que trates a la humanidad, tanto en tu persona como en la de cualquier otro, siempre como un fin al mismo tiempo y nunca sólo como un medio" (formulación del "imperativo categórico") y la que se conoce como la formulación del "Reino de los Fines" la expresa de la siguiente 
manera "obra de tal modo que la máxima de tu acción pueda formar parte de una legislación universal en un universal Reino de los Fines".

Pero la herencia kantiana también es recogida en la actualidad por otros filósofos que le impregnan matices diferentes. Por una parte, el norteamericano John Rawls, se preocupa por averiguar cuáles son los mínimos de justicia que comparten los ciudadanos de una sociedad plural y sostiene que una persona moral es aquella que desea ser feliz pero busca esa felicidad en el seno de una sociedad en la que ha de comportarse con justicia, compartiendo con los demás ciudadanos cargas y beneficios.

Por otra, Karl-Otto Apel y Jürgen Habermas promulgan desde la ética del discurso que los valores que realmente apreciamos son aquellos que conducen a un auténtico diálogo. Enfatizan en el "protagonismo" que debe caracterizar a los afectados por una norma, pues todos deben ser escuchados cuando se analizan aspectos que están estrechamente relacionados con su vida. Trabajar por la igualdad económica y cultural, la libertad, la solidaridad y la responsabilidad es imprescindible para alcanzar un verdadero diálogo.

Por lo tanto, como bien lo explica Savater (2003),

...elegir la humanidad es optar por un proyecto de autolimitación en lo tocante a cuanto podemos hacer, de simpatía solidaria ante el sufrimiento de los semejantes y de respeto ante la dimensión inmanejable que lo humano debe conservar para lo humano. Autolimitación, solidaridad, respeto: saberse humano no es aceptar un hecho- biológico o cultural- sino tomar una decisión y emprender un camino (Savater, 2003, p. 175).

En este proceso de humanización, resultan inspiradoras las sabias palabras de Gadamer cuando señalaba que "la educación es educarse y la formación es formarse", esto significa como ya lo han señalado otros pedagogos clásicos que "nos educamos a nosotros mismos" y el educador (sea el maestro, padre o tutor) participa con una modesta contribución.

Por lo tanto, somos nosotros mismos los propios escultores de nuestra existencia. Aunque la presencia del otro me permea de una u otra manera, debemos asumir con interés y constancia el propio perfeccionamiento, que pasa por supuesto, por nuestra propia motivación para superarnos, para alcanzar nuestras metas, por modelar nuestras actitudes y valores que nos ayuden a crecer como personas 
dignas No podemos esperar que los cambios nos vengan de fuera, debemos empezar por nosotros mismos, somos nosotros quienes tomamos o no la decisión para asumir esos cambios que nos ayudan a ser mejores, a sentirnos a gusto con lo que somos y tenemos.

La sociedad costarricense, ha heredado una tradición democrática que debemos cuidar y preservar para las futuras generaciones. No en vano, muchos de nuestros próceres ofrecieron su vida y su trabajo a la defensa de los más nobles ideales democráticos: la paz, justicia, trabajo, responsabilidad, compromiso y confianza. Aunque hemos experimentado en los últimos años fuertes vientos y tempestades de desilusión, incredulidad y pesimismo que han devastado los sentimientos que albergábamos en torno a la democracia y sus posibilidades de progreso y bienestar social; no podemos desfallecer y dar esta tarea por perdida, todo lo contrario, debemos trabajar, investigar y cultivar de nuevo la fe y la esperanza en la democracia, pues como bien lo afirma Held (2001) "estamos en la edad de la democracia o al menos así parece", lo que significa que necesitamos seguir creyendo en el ser humano y su enorme potencial para buscar transformaciones que no sólo le beneficien personalmente, sino que apele también al bienestar de quienes directa o indirectamente confían y necesitan de él para avanzar. El progreso no se construye en solitario, necesitamos que TODOS asumamos con entusiasmo, compromiso y responsabilidad las distintas tareas que cada uno tiene asignadas para que juntos podamos construir esa COSTA RICA con la que todos soñamos.

Urge que la formación ética se interiorice en lo más profundo de nuestro ser, que entendamos que más allá de memorizar unos valores y reconocer ciertas actitudes y hábitos, debemos interiorizarlos como un estilo de vida que nos ayuda a ser felices y también a favorecer la felicidad de los otros. Desde la forma en que nos comunicamos, de la manera en que trabajamos y aprovechamos el tiempo, desde cómo disfrutamos las horas libres y compartimos con los demás, desde la forma en que cumplimos nuestras responsabilidades como padres, madres, hijos, profesionales, estudiantes, políticos, administradores, religiosos... es decir, esta particular forma de SER y ACTUAR pone un sello de calidad $O$ no a nuestro desempeño como CIUDADANO COMPROMETIDO, como PERSONA ACTIVA y RESPONSABLE en el ejercicio de sus deberes y derechos...NECESITAMOS seguir creyendo en la PERSONA HUMANA, en su dignidad para afrontar retos y reconsiderar actitudes, en la capacidad para levantarse a pesar de las caídas, en la posibilidad de caminar pensando que podemos dejar una 
huella indeleble que el tiempo será incapaz de borrar, porque el COSTARRICENSE, puede seguir dando ejemplo al mundo de que es posible vivir en paz, justicia y fraternidad trabajando por la DEMOCRACIA y los PRINCIPIOS ÉTICOS que deben caracterizar a la humanidad. Dejemos que las palabras de Castells (1999) nos ayuden a concluir esta reflexión, cuando afirma,

...Si las personas están informadas, son activas y se comunican a lo largo del mundo; si la empresa asume su responsabilidad social; si los medios de comunicación se convierten en mensajeros, en lugar de ser el mensaje; si los actores políticos reaccionan contra el cinismo y restauran la fe en la democracia; si la cultura se reconstruye desde la experiencia: si la humanidad siente la solidaridad de la especie en todo el planeta; si afirmamos la solidaridad intergeneracional viviendo en armonía con la naturaleza; si emprendemos la exploración de nuestro yo interior, haciendo la paz con nosotros mismos. Si todo esto se hace posible por nuestra decisión compartida, informada y consciente, mientras aún hay tiempo, quizás entonces, por fin, seamos capaces de vivir y dejar vivir, de amar y ser amados. (p. 394)

\section{REFERENCIAS BIBLIOGRÁFICAS}

ARENDT, H. (1968). Between Past and Future. U.S.A.: Penguin Books.

Gedisa.

(1992). Hombres en tiempos de oscuridad. Barcelona,

(1998). The human condition. $2^{\text {nd }}$ ed. Chicago: University of Chicago Press.

ARISTOTLE. (1955,1978). Ethics. London: Penguin Classics.

BÁRCENA, F. (1997). El oficio de la ciudadanía. Introducción a la educación política. Barcelona: Paidós.

BUBER, M. (1998). Yo y Tú. Tercera edición. Madrid: Caparrós editores. 
BUXARRAIS, M.R. (1997). La formación del profesorado en Educación en Valores. Bilbao, Desclée de Brouwer

(2000). Tendencias y modelos de educación moral. Revista Diálogo Filosófico. Madrid: Diálogo Filosófico. Núm.47, pp. 196-220.

BUXARRAIS, M.R. y ZELEDON, M.P. (2004). La familia, un valor cultural. Tradiciones y educación en valores democráticos. Bilbao: Desclée de Brouwer.

CAMPS, V. (1993). Los valores en la educación. Madrid: Alauda.

CASTELLS, M. (1998). La sociedad red. Vol. I. Madrid: Alianza editorial.

- (1998). La era de la información. Economía, sociedad y cultura. Vol.II. El poder de la identidad. Madrid: Alianza editorial.

. (1998). La era de la información. Economía, sociedad y cultura. Vol.III. Fin de Milenio. Madrid: Alianza editorial.

COBO, J.M. (coord.) (2003). Ciudadanía y Educación. Número extraordinario de la Revista de Educación. Madrid: Ministerio de Educación, Cultura y Deporte.

CONROY, J. (2004). Betwixt \& Between. The liminal imagination, Education and Democracy. New York: Peter Lang Publisling.

COLES, R (1997). La inteligencia moral en los niños y de los adolescentes. Barcelona: Kairós.

CORTINA, A. (1992). Ética mínima. Introducción a la filosofía práctica. Madrid: Tecnos.

(1997). Ciudadanos del mundo. Hacia una teoría de la ciudadanía. Madrid: Alianza.

Tecnos.

(1997). Ética aplicada y democracia radical. Madrid: 
. (2000). La ética de la sociedad civil. Cuarta edición. Madrid: Alauda, Anaya.

Madrid: Trotta.

(2001). Alianza y contrato. Política, Ética y Religión.

DELORS, J. (1996). La educación encierra un tesoro. Madrid: Santillana/Unesco.

GADAMER, H.G. (2000). La educación es educarse. Barcelona: Paidós.

GARCÍA HOZ, V. (1989). El concepto de ser persona. Madrid: Rialp.

GIDDENS, A. (1999). La tercera vía. La renovación de la democracia. Madrid: Taurus, pp 95-103.

GUTMAN, A. (1999). Democratic Education. New Jersey: Princeton University Press

HABERMAS, J. (1990). Conciencia moral y acción comunicativa. Barcelona: Península.

HELD, D. (1996, 2001). Models of Democracy. Cambridge: Polity Press \& Blackwell Publishers.

KYMLICKA, W. y NORMAN, W. (1994). Return of the citizen: a survey of recent work on citizenship Theory. Ethics, p. 352-381.

LEVINAS, E. (2003). De otro modo que ser o más allá de la esencia. Salamanca: Ed. Sígueme.

MARTÍNEZ, M. y PUIG, J.M. (comps.). (1991). La educación moral. Perspectivas de futuro y técnicas de trabajo. Barcelona: GRAO

(1998). El contrato moral del educador. Condiciones para una nueva escuela. Bilbao: Desclée de Brouwer

MARTÍNEZ, et al. (2001). Un lugar Ilamado escuela, en la sociedad de la información y la diversidad. Barcelona: Ariel. 
MARTÍNEZ, BUXARRAIS, ESTEBAN (2002). La Universidad como espacio de aprendizaje ético. Revista Iberoamericana de Educación de la OEI $\mathrm{N}^{0}$ 29. Mayo-agosto. Puede revisarse ese mismo artículo en la siguiente página web: http://www.campusoei.org/valores/monografias/monografia03/reflexion02.htm.

NAVAL, C.; LASPADAS, J. (eds). (2000). La educación cívica hoy. Una aproximación interdisciplinar. Pamplona: Eunsa.

. (2001). Confiar: cuna de la sociabilidad humana. Costa Rica: Promesa.

NUCCI, L. (2003). La dimensión moral en la educación. Bilbao: Desclée de Brouwer.

PAYÁ, M. (2000). Educación en valores para una sociedad abierta y plural. Segunda edición. Bilbao: Desclée de Brouwer.

PETTIT, P. (2000). El republicanismo. Barcelona: Paidós.

RICOEUR, P. (1993). Amor y justicia. Madrid: Caparrós Editores.

SAVATER, F. (2002). El valor de educar. Barcelona: Ariel.

(2003). El valor de elegir. Barcelona: Ariel.

ZELEDON, M. P.; CHAVARRÍA, E. (2000). Educación infantil en valores desde la ética de la alteridad. San José: EUNED. (Premio Nacional Aquileo J. Echeverría 2000, del Ministerio de Cultura, Juventud y Deportes de Costa Rica)

- (2000). Programa Nacional de Formación en Valores. Universidad de Costa Rica- Ministerio de Educación Pública. San José, Costa Rica.

ZELEDÓN, M.P. (2003). La familia y la televisión: dos mundos que se encuentran. Monográfico virtual: Familias, medios de comunicación y valores democráticos. Organización de Estados Iberoamericanos.Junio-julio 2003. Recuperado de http://www.campusoei.org/valores/monografias/monografia01/reflexion06.htm 